Research Article

\title{
Valorization of Food Waste to Produce Eco-Friendly Means of Corrosion Protection and "Green" Synthesis of Nanoparticles
}

\author{
Georgii Vasyliev (iD) and Victoria Vorobyova $(\mathbb{D}$ \\ Department of Chemical Technology, National Technical University of Ukraine "Igor Sikorsky Kyiv Polytechnic Institute", \\ Kyiv 03056, Ukraine \\ Correspondence should be addressed to Georgii Vasyliev; g.vasyliev@kpi.ua
}

Received 18 October 2020; Revised 21 November 2020; Accepted 29 November 2020; Published 10 December 2020

Academic Editor: Ibrahim Cavusoglu

Copyright () 2020 Georgii Vasyliev and Victoria Vorobyova. This is an open access article distributed under the Creative Commons Attribution License, which permits unrestricted use, distribution, and reproduction in any medium, provided the original work is properly cited.

\begin{abstract}
Agrifood by-products are a key element within Europe's sustainable strategies. Valorization and reuse of zero-waste technologies are becoming more popular, and they are commonly named as "second-generation food waste management." The present study is directed to the valuable extracts of "green" organic compounds from the by-products of fruit and berry/vegetable crops, which can be revalorized in sustainable chemical technology and engineering, namely, in the production of "green" synthesis of nanoparticles and for the inhibition of corrosion and scaling of metals in corrosive media. Numerous types of agrifood by-products (rapeseed pomace, sugar beet pulp, fodder radish cake, grape pomace, and pomegranate peels) were investigated. The waste extracts for corrosion and scale inhibitors of mild steel in tap water were prepared by the conventional extraction method that uses 2-propanol and characterized by gas chromatography-mass spectroscopy (GC-MS). Inhibition of scaling and corrosion was investigated in thermal scaling conditions on the surface of the electrode manufactured from mild steel. The LPR technique was applied to measure the corrosion rate, and the scaling rate was determined gravimetrically. The extracts were found to inhibit the corrosion rate 2-3 times, while only radish cake extract inhibited both the corrosion and scaling rates. The waste extracts to produce nanoparticles were prepared by the ultrasound-assisted water extraction with subsequent oxidation by oxygen purge and characterized by liquid chromatography-mass spectroscopy (LC-MS). The aqueous grape pomace and pomegranate peel extracts were screened for total phenolic content (TPC) and total flavonoid content (TFC). The reduction capacity of the extracts was assessed using ferric reducing power (FRAP) and phosphomolybdenum (PM) assays. AgNPs were characterized by UV-Vis spectroscopy, dynamic light scattering (DLS), Fourier transform infrared spectroscopy (FT-IR), scanning electron microscope (SEM), and energy-dispersive X-ray spectroscopy (EDX) analysis. The particle size of AgNPs ranged between 40 and $50 \mathrm{~nm}$. The antimicrobial activity of AgNPs was tested against Escherichia coli using the agar diffusion method and optical density.
\end{abstract}

\section{Introduction}

Integrated utilization or recycling of food waste is a progressive direction of resource conservation. In almost every country in the world, the most important advances in scientific and technological progress and worldwide experience in the recycling of household and vegetable waste are used [1]. Within this direction is the idea of introducing into production not only low-waste but also zero-waste technologies. Involvement of waste in chemical technology production processes as a secondary raw material makes it possible to turn it into a valuable product, followed by its widespread use in the chemical materials industry [2-5], pharmaceutical, and cosmetic industries [6]. A significant amount of waste is generated in the processing of vegetable, fruit, and berry crops. Almost all these wastes are valuable secondary raw materials because they contain natural organic compounds. Therefore, the priority direction for the development of green chemical technology and engineering is the search and use of recycling materials for the receiving of organic compounds (plant extracts) from the waste of vegetable raw materials as well as the study of their composition and physicochemical properties. Further obtained extracts of "green" organic compounds can be used in the 
production of "green" synthesis of nanoparticles [7-11], for inhibition of corrosion and scaling of metals in corrosive media [12-16] and production of food additives and valuable nutrients, as a natural preservative and antioxidant in cosmetic products [17-19].

The food industry is an integrated branch of the agroindustrial sector and includes the processing of fruit, berry, and vegetable crops. Most waste is generated in the production of food products and in the beverage industry, which include pomaces of berries and vegetable and skins and stems of vegetable raw materials. The grape and pomegranate are widely cultivated in Ukraine and other European countries. Besides being consumed fresh, these are grown commercially to be processed into juices, jams, jellies, and nutraceutical ingredients. Similarly, pomace accounts for approximately $30 \%$ of the total waste of juice industry. After juice pressing, the waste pomegranate peels account for $12 \mathrm{wt} \%$ of the fruit. In the grape juice industry, about $45 \%$ of grape is utilized for juice and the remained part constitutes grape pomace. Moreover, several studies have demonstrated that fruit pomaces display antioxidant and radical scavenging activity. According to the composition of grape pomace and pomegranate peel extracts, they contain a large amount of phenolic compounds, flavonoids, and organic acids; thus, the extracts are promising antioxidants and "green reductants" to obtain nanoscale materials.

The process of $\mathrm{Ag}^{+}$cation reduction and nanoparticle formation may require a significant amount of time (12-150 hours) [20-22]. The reason for this can be the chemical modification of the plant extract with time that increases its reduction ability. Recent studies report the use of oxidized amylose as reducing agents [20]. Chemical transformations that require several hours or days can be accelerated and completed in few minutes by oxygen purge of the prepared extract. It was established that silver nanoparticles can be synthesized using previously oxidized extract of black currant and apricot pomaces as a reducing and capping agent $[21,22]$. So, the search for the ways to intensify the "green" synthesis is a challenging task. In view of the effective synthesis of AgNPs using previously oxidized extract, it is important to investigate the efficiency of this approach for other types of plant raw materials.

Another popular area in the field of cost-effective treatment of industrial waste research is the development of "green," environmentally friendly, biodegradable reagents (anticorrosion and antiscale reagents) based on organic compounds extracted from food and agricultural products processing. The antiscalant effect of naturally occurring plant extracts (Bistorta officinalis, Azadirachta indica, Punica granatum hull and leaf, seaweeds, palm leaves, Aloe vera, corn stalks, Momordica charantia, Paronychia argentea, Spergularia rubra, and Parietaria officinalis) for cooling systems was studied by many authors [23-25]. The authors suggested that the scale inhibition efficiency of these extracts may be due to the involvement of phenolic compounds or polysaccharides. In particular, by-products of sugar production, industrial radish, and rape processing result in the generation of by-products containing valuable anticorrosion and antiscale compounds that can be extracted and further valorized as anticorrosion products. According to the literature, radish seed extract was tested as a mild steel corrosion inhibitor in $1 \mathrm{MH}_{2} \mathrm{SO}_{4}$ solution [26]. The inhibitory effect of radish leaf extract (RLE) on mild steel corrosion in $0.5 \mathrm{MH}_{2} \mathrm{SO}_{4}$ was studied by the weight loss and electrochemical techniques [27]. Furthermore, the black radish juice was found to inhibit tin corrosion which was studied by Radojčić et al. [28]. In another study, Selvi et al. evaluated the corrosion inhibition behavior of beetroot extract in well water in the presence of $\mathrm{Zn}^{2+}$ [29]. The significant inhibition performance of the rape grist extract for steel corrosion in neutral media was observed [30]. At the same time, extracts of these by-products have not ever been studied as both corrosion and scale inhibitors. It is worse to point out that many extracts provide corrosion inhibition effects but do not have antiscale properties.

Thus, the study of the possibility to use plant waste in different areas of chemical technology and to create zerowaste technologies by the use of food waste is an urgent issue. For European countries, the most typical types of waste were identified: grape, pomegranate processing residues (pomace and peels), and processing residues of radish, rape, and beetroots.

The aims of the present study are as follows:

(1) To investigate the natural raw materials from agricultural and food industry (rapeseed pomace, sugar beet pulp, and fodder radish cake) as potential sources of corrosion and scale inhibitors for mild steel in tap water

(2) To assess the prospects of the use of plant extracts (grape pomace and pomegranate peels) as a reducing agent in nanoparticle production

\section{Materials and Methods}

2.1. Extract Preparation. The raw material powder and ethanol were mixed in the weight ratio of $1: 10$. The rapeseed pomace, sugar beet pulp, and fodder radish cake extracts were prepared by maceration for $24 \mathrm{~h}$ in ethanol. The resulted mixture was filtered with a Whatman filter grade 3 paper to remove solid contents.

In the second case, the grape pomace (GPE) and pomegranate peel extract (PPE) were obtained from the pomaces remained after mechanical pressing of the fresh fruits to produce juices. The grape pomace and pomegranate peels were mixed with distilled water in the $1: 10(\mathrm{w} / \mathrm{v})$ ratio at $25^{\circ} \mathrm{C}$. The mixture was placed in the ultrasound bath. The ultrasound of $27 \mathrm{kHz}$ frequency and $6 \mathrm{~W} / \mathrm{cm}^{2}$ intensity was applied for 2 hours. The sonication process was coupled with air bubbling through the solution to intensify extract oxidation [21, 22]. The oxidized extract appeared to be highly efficient in AgNPs synthesis compared to nonoxidized extract. During the sonication, the air was continuously bubbled through the solution. Due to the high intensity of sonication, the ultrasound cavitation occurs in the solution intensifying the extraction process. At the end of the process, the temperature of the solution reached $40^{\circ} \mathrm{C}$ due to the influence of ultrasound. After the extraction, the solution was filtered through a paper filter. 
2.2. GC-MS and LC-MS Extract Composition Analyses. The obtained extracts were analyzed with LC-MS and GCMS techniques. A detailed description of the protocol of the chromatography mode is presented in previously published works $[15,23]$.

\subsection{Total Polyphenol and Flavonoid Contents in the Extracts.} The total polyphenol content (TPC) was determined using the Folin-Ciocalteu assay according to the method of Sánchez-Rangel et al. [31]. The results were expressed as milligrams of gallic acid equivalent per gram of the extract (mg GAE/g).

The total flavonoid content (TFC) was determined by the aluminum chloride assay according to the method of Arvouet-Grand et al. [32]. The final values were expressed as milligrams of quercetin equivalent per gram of the extract (mg QCE/g).

2.4. Antioxidant Capacity of the Extracts. The total antioxidant activity of the extracts was determined by the phosphomolybdenum reduction assay described by Prieto et al. [33]. The antioxidant activity is expressed as milligrams of ascorbic acid equivalent per gram of the extract (mg ASE eq/g extract).

Scavenging of 2, 2-diphenyl-1-picrylhydrazyl (DPPH) radicals and 2, 2' -azino-bis-(3-ethylbenzothiazoline-6-sulfonic acid) (ABTS) were performed according to the method of Taipong et al. [34].

The FRAP assay was performed as described by the method of Rhimi et al. [35]. The FRAP assay was determined based on the method that involves assessing the ability of the test extract to reduce ferricyanide $\left(\mathrm{Fe}^{3+}\right)$ to form potassium ferrocyanide $\left(\mathrm{Fe}^{2+}\right)$, which then reacts with ferric chloride to form a ferric ferrous complex that has an absorption maximum at $700 \mathrm{~nm}$.

2.5. Characterization of Anticorrosion and Antiscalant Properties of the Extracts. Antiscalant efficiency of the extract was tested in thermal scaling conditions according to the method that was described in previously published works [36]. Corrosion inhibition efficiency of the extract was determined with linear polarization resistance technique (LPR) in thermal scaling conditions [37-39]. The morphology of the surface after thermal scaling was studied with the use of a SEM-106I Selmi microscope (Ukraine) operated at $20 \mathrm{kV}$. The steel rings were removed from the Pyrex tube, dried, and sent to analyses.

2.6. Synthesis of AgNPs Using the Extracts. Synthesis of AgNPs using the extracts was performed as described in previously published works $[21,22]$. The previously oxidized grape pomace and pomegranate peel extracts were used as environmentally friendly reducing and capping agents to synthesize silver nanoparticles for the first time.

2.7. UV-Visible Spectroscopy of AgNPs. The synthesized silver nanoparticles were investigated using an UV-Vis spectrophotometer (Shimadzu-2450 UV-Vis spectrophotometer) in the range between 200 and $-800 \mathrm{~nm}$ according to the method of Ankamwar et al. [4]. The samples were diluted with deionized water, and UV-visible spectra were recorded using a $1 \mathrm{~cm}$ quartz cuvette at $25^{\circ} \mathrm{C}$.

2.8. Dynamic Light Scattering (DLS) of AgNPs. Characterization of the particle size and zeta potential of the AgNPs were carried out according to the method described previously $[5,8]$. The particle size and zeta potential of the AgNPs were carried out by Zetasizer (Malvern Zetasizer Nano-ZS, Malvern Instruments, UK). The sample was prepared by diluting the $10 \mathrm{ml}$ of the AgNPs solution in $10 \mathrm{ml}$ of distilled water. After that, $10 \mathrm{ml}$ of sample solution was put in the cuvette. The cuvette was placed in the cell holder and scanned in the range of $1-100 \mathrm{~nm}$ using a fixed angle of $173^{\circ}$.

2.9. Scanning Electron Microscopy of AgNPs. A scanning electron microscope (SEM) was used to examine the morphology of the synthesized AgNPs. A drop of colloidal system of extract-AgNPs was applied on the carbon-coated copper plate, and an image was taken at an acceleration voltage of $10 \mathrm{kV}$. EDX analysis was conducted with the same instrument to confirm the elemental composition of the sample.

2.10. Fourier Transform Infrared Spectroscopy (FT-IR) of AgNPs. FT-IR spectroscopy measurements were carried out to identify the functional groups which were responsible for capping the AgNPs and involved in the synthesis of AgNPs. FT-IR spectra of extracts and extract-AgNPs were measured by using a Bruker Tensor 27 FTIR spectrometer with a diamond crystal accessory in a spectral range of $4000-600 \mathrm{~cm}^{-1}$ with a resolution of $4 \mathrm{~cm}^{-1}$.

2.11. Antibacterial Assay of AgNPs. The minimum bactericidal concentration (MBC) was determined as the lowest concentration of AgNPs solution in the tube that caused no significant changes of turbidity, and no colony was found in Endo agar [35]. Minimum inhibitory concentration (MIC) was estimated as a concentration in the tube in which turbidity (optical density) was doubly decreased. Low values of optical density, at least less than 0.07 , as well as the control absence of bacterial growth on Endo agar allowed us to determine the minimal bactericidal concentration of each sample of AgNPs solution.

\section{Results and Discussion}

3.1. By-Products of Plant Food Processing as Corrosion and Scale Inhibitors. The priority area of reducing the material consumption is to involve waste in the chemical production process of corrosion and scale inhibitors [37-40]. Three industry by-products were used, rapeseed pomace from the wastes of production of edible oil, sugar beet pulp from the wastes from sugar production, and fodder radish cake. 
The key factor that determines the effectiveness of using a plant extract as corrosion or scale inhibitor of mild steel in natural water is the component composition of them [15]. Gas chromatography-mass spectrometry (GCMS) analysis was carried out to analyze the chemical composition of extracts. The results of the GC-MS analysis of the radish cake extract (RCE) are presented in Table 1. This extract is characterized by the presence of anthocyanidins including cyanidin $(6.7 \%)$ and pelargonidin (6.9\%), isothiocyanates such as 3-(methylthio)propyl isothiocyanate (iberverin) (4.2\%), 4-pentenyl isothiocyanate $(8.3 \%)$, 4-methylpentyl isothiocyanate $(3.1 \%)$, 3-butenyl isothiocyanate (3.9\%), 4-(methylthio)-3butenyl isothiocyanate $(5.2 \%)$, 4 -(methylthio)butyl isothiocyanate (erucin) (6.4\%), 5-(methylthio)pentyl isothiocyanate (berteroin) (6.9\%), and L-sulforaphane (1.1\%). In addition, other major compounds included phenolic compounds such as pyrogallol, vanillic, and gallic acids, and eugenol. In addition, fatty acids were detected in a considerable amount $(8.9 \%)$ in the extract.

The main compounds extracted from the rape cake are given in Table 2. A total of 18 compounds were identified, including saturated and unsaturated fatty acids, aldehydes, ketones, terpenes, and glycosides. The major phytocompounds identified in the rape cake extract are $3^{\prime}, 5^{\prime}$-dimethoxyacetophenone (28.3\%), 4-hydroxy-3,5dimethoxybenzaldehyde (20.5\%), and (9Z)-octadec-9enoic acid (12.2\%). Other 15 compounds were present in $39.7 \%$ of the total compounds.

The GC-MS analysis of the sugar beet pulp extract revealed the presence of six compounds (Table 3 ). The maximum amount of the components present in the sugar beet pulp extract are sugar acid ((2S, 3R, 4S, 5R)-2, 3, 4, 5tetrahydroxy-6-oxo-hexanoic acid) (36.9\%) and sophorose (11.2\%). These compounds represented over $48 \%$ of the total compounds in the extract.

3.2. Thermal Scaling Test. The scale mass growth rate on the surface of mild steel is given in Figure 1. The deposition rate in tap water is $7.5 \mu \mathrm{g} /\left(\mathrm{h} \cdot \mathrm{cm}^{2}\right)$. It remains constant during the test. In contrast to tap water, when the radish cake extract is added, the scale deposition is reduced to $1.6 \mu \mathrm{g} /\left(\mathrm{h} \cdot \mathrm{cm}^{2}\right)$ meaning that the antiscaling efficiency is $78.7 \%$. Rape pomace extract does not cause any influence on the scale deposition rate, and the scaling rate is the same as in the tap water. Sugar beet pulp extract appears to accelerate scaling. The scale deposition rate in tap water exceeds $20 \mu \mathrm{g} /\left(\mathrm{h} \cdot \mathrm{cm}^{2}\right)$. Such a high deposition rate is probably caused by the deposition of extract components on the electrode surface, simultaneously with calcium carbonate. So, only RCE slows down the deposition of calcium carbonate even at the temperature of $100^{\circ} \mathrm{C}$.

Possible mechanism of scale inhibition could be the formation of soluble complexes with calcium ions. Such complexes prevent the deposition of calcium carbonate, keeping calcium ions in the soluble form. The mechanisms for scale inhibition by the extract are associated with the active functional groups $(\mathrm{C}=\mathrm{O},-\mathrm{OH}$, and $-\mathrm{COOH}$ groups $)$ of the main compounds of the extract [41-47]. These substances, which have hydroxyl and/or carboxyl functional groups that interact with divalent ions such as $\mathrm{Ca}^{2+}$, are known to form water-soluble complexes with calcium ions $[15,23-25]$. In addition to this, carboxyl-terminated anthocyanidins have a larger surface area, which can chelate with more $\mathrm{Ca}^{2+}$.

According to GC-MS, phenolic compounds such as anthocyanidins, phenolic acids, polysaccharides, sugar acids, and saturated and unsaturated fatty acids were found in the rape pomace and sugar beet pulp extract, while the radish cake extract additionally contains isothiocyanates with $\mathrm{N}=\mathrm{C}=\mathrm{S}$ functional groups that can dimerize [15]. The mechanisms for scale inhibition of the radish cake extract have been associated with both the formation of the protective film on the surface of steel by compounds such as isothiocyanates and saturated fatty acids and the formation of water-soluble complexes of phenolic derivatives (pyrogallol, vanillic, and gallic acids, eugenol, and polysaccharides) with divalent ions such as $\mathrm{Ca}^{2+}$.

3.3. Corrosion Inhibition. The instantaneous corrosion rate of mild steel determined with LPR technique in thermal scaling conditions is given in Figure 2. In tap water, the corrosion rate of mild steel right after immersion is around $0.8 \mathrm{~mm} /$ year and decreases with the boiling time due to the formation of the scale layer that acts as a diffusion barrier and reduces oxygen supply to the surface. In tap water with added extracts, the corrosion rate decreases in the first hours. The corrosion rate reduction with radish cake and sugar beet pulp extracts is very close; however, rape pomace extract appears to be a more efficient corrosion inhibitor. In the first 10 hours, corrosion rate reaches $0.1 \mathrm{~mm} /$ year. As scale deposition progresses, the corrosion rate in both tap water and inhibited solutions decreases; however, in tap water, the decrease is faster because more scale is deposited. The thicker the scale layer, the less porous it becomes, and thus, the corrosion rate is lower. After $80 \mathrm{~h}$ of boiling, the corrosion rate in the solutions coincides at $0.2 \mathrm{~mm} / \mathrm{year}$ and continued to decrease till the corrosion rate of $0.1 \mathrm{~mm} /$ year is reached.

3.4. Surface Film Formation. The SEM images of the scaled steel surface are given in Figure 3. The scale deposited from tap water has a regular structure. The crystals are $60-80 \mu \mathrm{m}$, and the layer is uniform. In the presence of RCE, the crystals are much smaller, and the presence of the organic film is clearly observed on the surface. Figure 3(c) demonstrates the charging effect of SEM when the electrons are accumulated in the organic film. SEM analysis clearly demonstrates the formation of the organic surface film that acts as a barrier level to reduce the supply of oxygen and calcium carbonate, thus reducing scaling and corrosion. The scale crystals formed in tap water containing rape cake extract are significantly larger. At the same time, the crystals in sugar beet pulp extract solution are smaller compared to the crystals obtained in tap water, but an amorphous surface film is 
TABLE 1: GC-MS analysis results of radish cake extract.

\begin{tabular}{|c|c|c|c|}
\hline $\mathrm{RT}(\min )^{\mathrm{a}}$ & Compound & $\mathrm{RI}^{\mathrm{b}}$ & Percentage (\%) \\
\hline 2.91 & 3-(Methylthio)propyl isothiocyanate ${ }^{\mathrm{a}, \mathrm{b}}$ & 1305 & 4.2 \\
\hline 3.02 & Pyrogallol acids & 1370 & 2.9 \\
\hline 6.96 & 4-Pentenyl isothiocyanate ${ }^{\mathrm{a}, \mathrm{b}}$ & 1075 & 8.3 \\
\hline 7.31 & 4-Methylpentyl isothiocyanate ${ }^{\mathrm{a}, \mathrm{b}}$ & 1139 & 3.1 \\
\hline 10.02 & Undecane $^{\mathrm{a}, \mathrm{b}}$ & 1100 & 1.9 \\
\hline 10.41 & 2-Methoxy-4-(prop-2-en-1-yl)phenol ${ }^{\mathrm{a}, \mathrm{b}}$ & 1340 & 2.5 \\
\hline 10.62 & 4-Hydroxy-3-methoxybenzoic acid ${ }^{\mathrm{a}, \mathrm{b}}$ & 1636 & 2.8 \\
\hline 10.92 & Dodecane $e^{\mathrm{a}, \mathrm{b}}$ & 1200 & 1.0 \\
\hline 12.42 & 4-(Methylthio)-3-butenyl isothiocyanate & 1433 & 5.2 \\
\hline 12.73 & 4-(Methylthio)butyl isothiocyanate ${ }^{\mathrm{a}, \mathrm{b}}$ & 1408 & 6.4 \\
\hline 12.99 & Gallic acid a,b $^{\mathrm{a},}$ & 1943 & 2.7 \\
\hline 13.78 & 5-(Methylthio)pentyl isothiocyanate ${ }^{\mathrm{a}, \mathrm{b}}$ & 1250 & 6.9 \\
\hline 14.24 & L-Sulforaphane ${ }^{\mathrm{a}}$ & - & 1.1 \\
\hline 15.27 & Dextrose $^{\mathrm{a}}$ & - & 3.7 \\
\hline 15.49 & Tridecane $^{\mathrm{a}, \mathrm{b}}$ & 1300 & 1.9 \\
\hline 16.11 & Dodecanoic acid ${ }^{\mathrm{a}, \mathrm{b}}$ & 1645 & 0.8 \\
\hline 16.33 & Cyanidin ${ }^{\mathrm{a}}$ & & 6.7 \\
\hline 18.77 & Hexadecanoic acid ${ }^{\mathrm{a}, \mathrm{b}}$ & 2059 & 2.2 \\
\hline 19.92 & Pelargonidin ${ }^{\mathrm{a}}$ & - & 6.9 \\
\hline 21.00 & Octadecanoic acid ${ }^{\mathrm{a}, \mathrm{b}}$ & 2157 & 5.9 \\
\hline 24.11 & Methyl linoleate $\mathrm{a}^{\mathrm{a}, \mathrm{b}}$ & 2133 & 5.1 \\
\hline 25.16 & Sophorose $^{\mathrm{a}}$ & - & 7.1 \\
\hline
\end{tabular}

${ }^{a}$ RT: retention time; STD: standard compound; NIST $14 .{ }^{b}$ RI: Kovats retention indices (RI) determined using a commercial hydrocarbon mixture (C9-C25) on the HP-5MS column.

TABLE 2: GC-MS analysis results of rape pomace extract.

\begin{tabular}{|c|c|c|c|}
\hline $\mathrm{RT}(\mathrm{min})^{\mathrm{a}}$ & Compound & $\mathrm{RI}^{\mathrm{b}}$ & Percentage (\%) \\
\hline 8.41 & Guanosine $^{\mathrm{a}}$ & - & 10.4 \\
\hline 8.57 & Sucrose ${ }^{\mathrm{a}}$ & - & 1.2 \\
\hline 8.92 & Xanthosine $\mathrm{e}^{\mathrm{a}, \mathrm{b}}$ & 1758 & 4.3 \\
\hline 9.48 & 4-Hydroxy-3, 5-dimethoxybenzoic acid a,b & 1893 & 28.3 \\
\hline 10.37 & 4-Hydroxy-3, 5-dimethoxybenzaldehyde ${ }^{\mathrm{a}, \mathrm{b}}$ & 1662 & 20.5 \\
\hline 10.42 & Acetic acid ${ }^{\mathrm{a}, \mathrm{b}}$ & 1090 & 1.6 \\
\hline 15.14 & $n$-Cyclohexyl-4-hydroxybutyramide $\mathrm{e}^{\mathrm{a}, \mathrm{b}}$ & & 1.6 \\
\hline 16.33 & $(9 \mathrm{Z}, 12 \mathrm{Z})-9,12$-Octadecadienoic acid $^{\mathrm{a}, \mathrm{b}}$ & 2129 & 4.8 \\
\hline 16.88 & Hexadecanoic acid ${ }^{\mathrm{a}, \mathrm{b}}$ & 2059 & 4.1 \\
\hline 18.76 & (9Z)-Octadec-9-enoicacid ${ }^{\mathrm{a}, \mathrm{b}}$ & 2134 & 12.2 \\
\hline 19.92 & Octadecanoic acid ${ }^{\mathrm{a}, \mathrm{b}}$ & 2157 & 2.0 \\
\hline 22.75 & Pyrrolidine, 1-(1-oxo-7,10-hexadecadienyl $)^{\mathrm{a}}$ & - & 0.9 \\
\hline 22.97 & Ethanamine, $2,2^{\prime}$-oxybis[N, N-dimethyl]- ${ }^{\mathrm{a}}$ & - & 0.9 \\
\hline 23.37 & 7-Dehydrodiosgenin ${ }^{\mathrm{a}}$ & - & 2.1 \\
\hline 23.87 & Campesterol $^{\mathrm{a}}$ & - & 1.1 \\
\hline 23.99 & $\gamma$-Sitosterol ${ }^{\mathrm{a}, \mathrm{b}}$ & 3299 & 1.2 \\
\hline 24.56 & $\beta$-Sitosterol ${ }^{\mathrm{a}, \mathrm{b}}$ & 3299 & 1.1 \\
\hline 25.03 & Ergosta-5, 22-dien-3-ol & - & 2.4 \\
\hline
\end{tabular}

${ }^{a}$ RT: retention time; STD: standard compound; NIST $14 .{ }^{b}$ RI: Kovats retention indices (RI) determined using a commercial hydrocarbon mixture (C9-C25) on the HP-5MS column.

found around them, probably due to the deposition of extract components.

3.5. By-Products of Plant Food Processing for the Manufacture of Nanomaterials. The synthesis of metal nanoparticles using environmentally friendly "green" compounds extracted from wastes and serving as both reducing and capping agent is especially promising for the cost-effective treatment/valorization of industrial wastes. Different wastes have been used for the synthesis of AgNPs, such as banana and orange peel, papaya peel, tea and grape wastes, and sugarcane bagasse. However, further search for large tonnage waste is promising for the production of nanomaterials which is an important task, both from the side of creating resource-saving technologies for waste processing and for the development of sustainable chemistry concepts in the field of chemical synthesis of nanomaterials. For Ukraine and other countries, it is interesting to use the waste generated during the processing of fruit and berry crops, such as apricot, grapes, pomegranate, and currant. These agroindustrial 
TABLE 3: GC-MS analysis results of the sugar beet pulp extract.

\begin{tabular}{|c|c|c|c|}
\hline $\mathrm{RT}(\mathrm{min})^{\mathrm{a}}$ & Compound & $\mathrm{RI}^{\mathrm{b}}$ & Percentage (\%) \\
\hline 5.21 & 1-Methyl-4-(prop-1-en-2-yl)cyclohex-1-ene ${ }^{\mathrm{a}}$ & - & 3.7 \\
\hline 5.79 & Unknown & & - \\
\hline 6.96 & $(2 S, 3 R, 4 S, 5 R)-2,3,4,5$-Tetrahydroxy-6-oxo-hexanoic acid & - & 36.9 \\
\hline 9.24 & (E)-3-(4-Hydroxy-3-methoxy-phenyl)prop-2-enoic acid ${ }^{\mathrm{a}, \mathrm{b}}$ & 2091 & 4.4 \\
\hline 10.32 & Sophorose $\mathrm{a}^{\mathrm{a}}$ & - & 11.2 \\
\hline 10.48 & Unknown & - & - \\
\hline 12.51 & Unknown & - & - \\
\hline
\end{tabular}

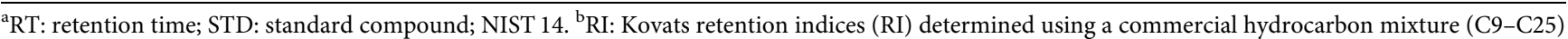
on the HP-5MS column.

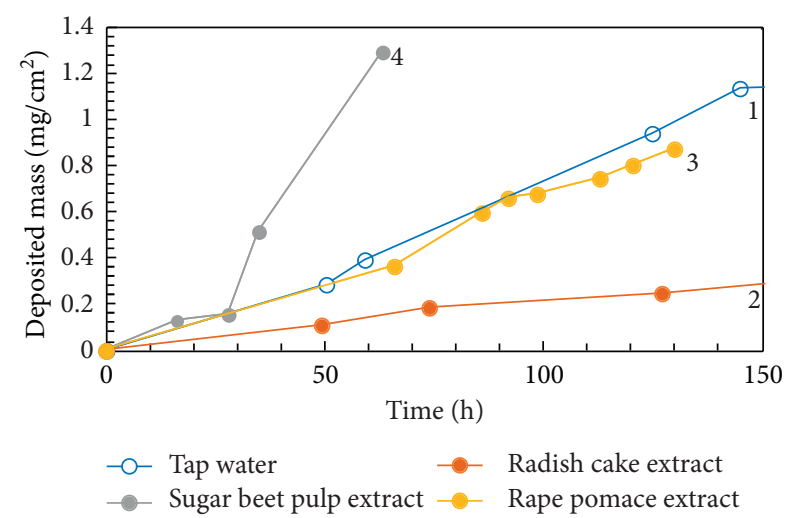

Figure 1: Scaling rate of mild steel in tap water at $100^{\circ} \mathrm{C}$ : (1) blank; (2) with $10 \mathrm{~mL} / \mathrm{L}$ of radish cake extract; (3) with $10 \mathrm{~mL} / \mathrm{L}$ of rape pomace extract; (4) with $10 \mathrm{~mL} / \mathrm{L}$ of sugar beet pulp extract.

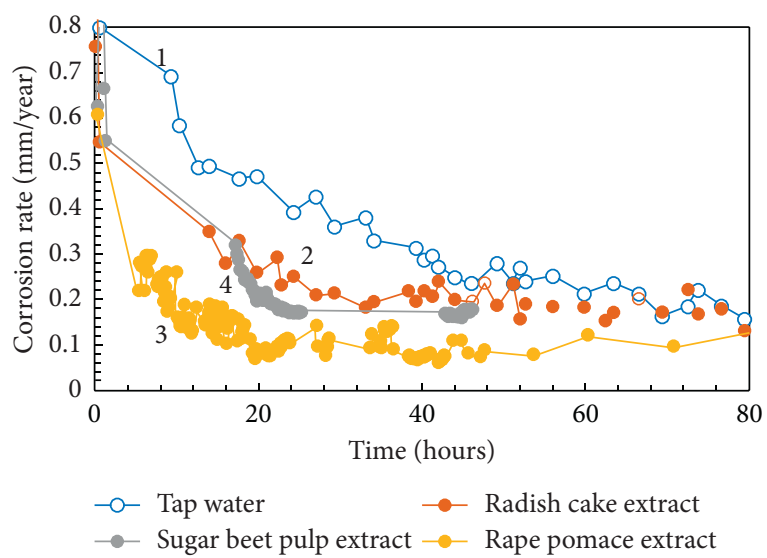

FIGURE 2: LPR corrosion rate of mild steel in tap water at $100^{\circ} \mathrm{C}:(1)$ blank; (2) with $10 \mathrm{~mL} / \mathrm{L}$ of radish cake extract; (3) with $10 \mathrm{~mL} / \mathrm{L}$ of rape pomace extract; (4) with $10 \mathrm{~mL} / \mathrm{L}$ of sugar beet pulp extract.

wastes are readily available, eco-friendly, cost-effective, and can be easily reused. Agrofood wastes are regarded as a highly multicomponent system for nanoparticle synthesis because they contain a wide range of green organic compounds with high reducing potential. Usually, for the synthesis of nanoparticles, aqueous and alcoholic extracts of plant materials are used. These are the classic solvents that were initially used in the extraction process and further to obtain nanoparticles. However, it was found that the preliminary modified extract through oxidation modification (oxygen purge) increases its reduction ability $[21,22]$.

The prospects of the use of plant extracts (grape pomace and pomegranate peels) as a reducing and capping agent to produce nanoparticles were investigated (Table 4). In particular, the component composition and radical scavenging of the grape pomace and pomegranate peel extracts, obtained by ultrasound-assisted water extraction, were studied. The obtained extracts were used to obtain silver nanoparticles through "green" synthesis, and the antibacterial properties of the nanoparticles were estimated.

Characterization of the plant extracts that were previously oxidized is an essential requirement to have information on the chemical composition and reducing power. To our knowledge, this is the first application of the method of preliminary modification extract through oxidation and the next analysis of the extracts by the LC-MS method.

The extracts from grape pomace and pomegranate peels were analyzed by liquid chromatography-mass spectrometry (LC-MS). The main groups both quantitatively and qualitatively of the compounds in grape pomace extract were phenolic acids, anthocyanins, and stilbenes. The major percentage corresponded to phenolic compounds. p-Coumaric acid, 3, 4-dimethoxyphenylacetic acid, and delphinidin-3-O-glucoside were found in large amounts in the grape pomace extract. The results of the chemical analysis of previously oxidized grape pomace extract are shown in Table 4, and a comparative analysis of the major components with respect to studies reported in the literature $[47,48]$ indicates that oxidation products prevail in the composition.

Table 5 shows the composition of the pomegranate peel extract. Pomegranate peel extract mainly consists of phenolic compounds, predominantly chlorogenic acid (7.5\%), ellagic acid (7.8\%), and caffeic acid (4.7\%), and major quantities of punicalagin (granatin $\mathrm{A}$ and granatin $\mathrm{B}$ ) (13.4\%). The results of LC-MS analyses of the extracts are in agreement with the literature data [7, 49-51].

Several articles described the significant role of phenolic compounds in the reduction capacity of plant extracts $[51,52]$. Therefore, the total phenolic (TPC) and flavonoid contents of the extracts were investigated (Figure 4). The total polyphenol content was determined using the Folin-Ciocalteu assay according to the method of SánchezRangel et al. [31]. 

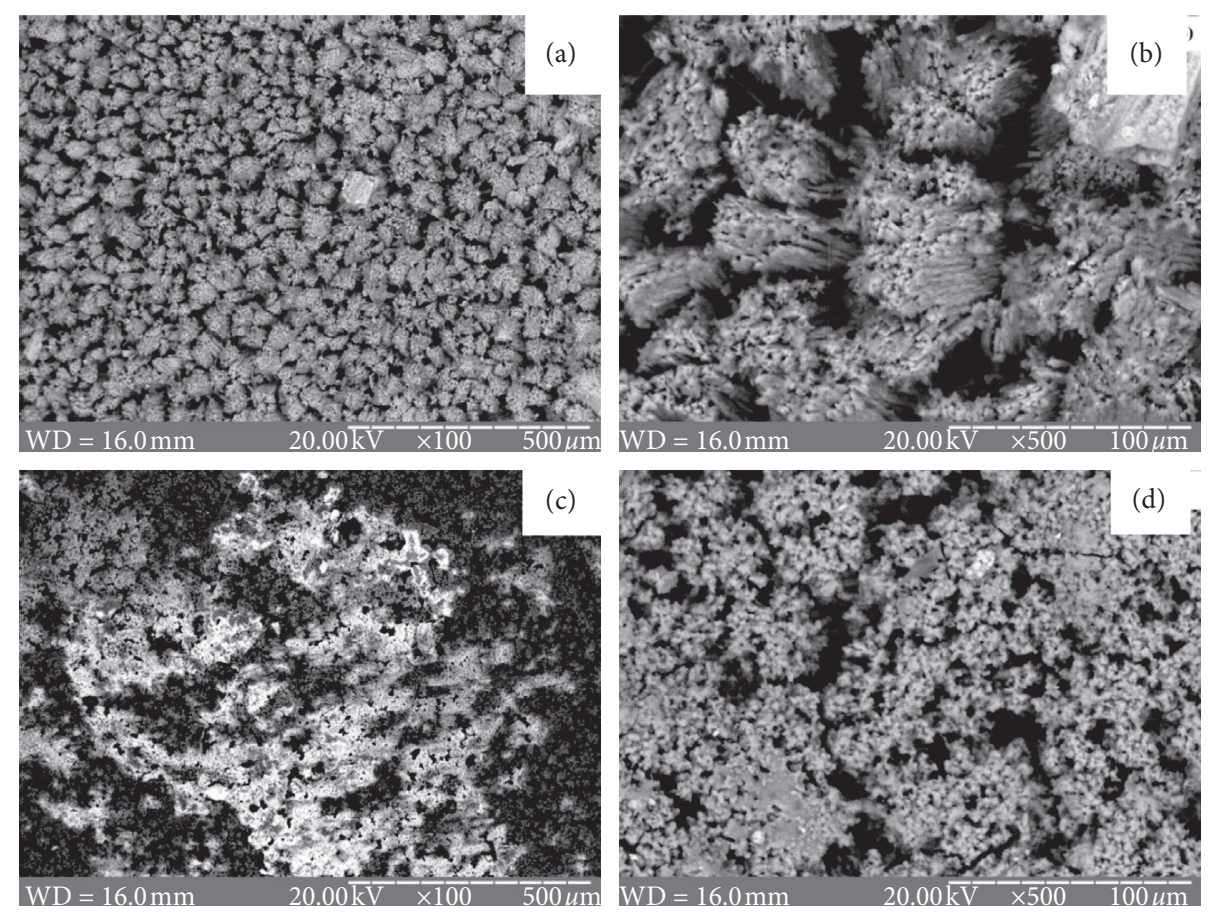

FIGURE 3: SEM images of steel scaled surface after $150 \mathrm{~h}$ of boiling in tap water with addition: (a) blank; (b) $10 \mathrm{~mL} / \mathrm{L}$ of rape pomace extract; (c) $10 \mathrm{~mL} / \mathrm{L}$ of radish cake extract; (d) $10 \mathrm{~mL} / \mathrm{L}$ of sugar beet pulp extract.

It was found that the pomegranate peel extract had higher phenolic content of $108.5 \pm 1.8 \mathrm{mg}$ GAS/100 g extract while grape pomace extract phenolic content was $64.2 \pm 1.8 \mathrm{mg}$ GAS $/ 100 \mathrm{~g}$ extract. The total flavonoid content of the extracts is shown in Figure 4. The total flavonoid content of the extracts was increased in the direction as the total polyphenol content. This finding was also confirmed by the chromatographic analysis, which indicated that the pomegranate peels contained more phenolic compounds than the grape pomace extract.

Similar findings were also observed in the reducing power assay (FRAP) (Figure 5) and by the phosphomolybdenum method (Figure 6) where the pomegranate peel extract was more active. The highest total antioxidant capacity $(571.25 \mathrm{mg}$ GAE/g extract) was obtained for grape pomace extract. Figure 6 shows the dose-response relation for the reducing power of the extracts. Reducing powers of the extracts were found to increase with increasing concentrations.

The reducing activity of the extract is generally associated with the presence of compounds, which has been proven to exert reduction reaction and formation of $\mathrm{Ag}^{+}$cations in the process of NPs synthesis. Total reducing activities of grape pomace and pomegranate peel extracts are given in Figure 6. It was shown that the contents of reductive substances in the extracts were abundant, which was beneficial to the formation of silver nanoparticles.

3.6. Determination of the Synthesis Efficiency. The potential of the $\mathrm{Ag}^{+} \mid \mathrm{Ag}$ electrode variation with time is given in Figure 7. The electrode potential corresponds to $\mathrm{Ag}^{+}$concentration in the solution, and thus, the synthesis process can be monitored. A sharp decrease of the potential is caused by $\mathrm{AgNO}_{3}$ mixing with the extract and the beginning of the synthesis.

Calculated degree of conversion of Ag in the "green" synthesis with extracts is given in Table 6. The highest yield of AgNPs was obtained with pomegranate extract (99.7\%). The higher abundance of phenolic acids in the pomegranate peel aqueous extract may be responsible for the improved AgNPs synthesis with it.

3.7. Spectrophotometric Characterization of Ag-NPs. The synthesis of the AgNPs in liquid solution was observed by measuring the absorption spectra at a wavelength range of 200-1100 nm. In the UV-Vis spectrum, a single, strong, and broad surface plasmon resonance peak was observed at $440 \mathrm{~nm}$ that confirmed the synthesis of AgNPs (Figure 8).

The DLS measurements revealed that the average hydrodynamic size of the synthesized GPE-AgNPs was $34.68 \pm 4.95 \mathrm{~nm}$, and the average zeta potential was $-25.31 \mathrm{mV}$ (Table 7). The average particle size was found to be higher for GPE-AgNPs in comparison with the samples of PPE-AgNPs. AgNPs prepared by pomegranate peel extracts most often are negatively charged. Several reports demonstrated similar negative values of zeta potential for metallic nanoparticles stabilized with different polyphenols [53, 54]. These results are consistent with the earlier results of the plant-mediated synthesis of AgNPs, including orange peel and others.

The EDX spectra of "green" synthesized nanoparticles are depicted in Figure 9. AgNPs display typical peaks in the range $2.7-3.4 \mathrm{keV}$. The presence of another peak in the 
TABLE 4: LC-MS analysis results of the aqueous grape pomace extract.

\begin{tabular}{|c|c|c|c|c|}
\hline $\begin{array}{l}\mathrm{RT}^{\mathrm{a}} \\
(\mathrm{min})\end{array}$ & Compound & $\mathrm{RI}^{\mathrm{b}}$ & {$[\mathrm{M}-\mathrm{H}]^{-\mathrm{c}}$} & $\begin{array}{c}\text { Percentage } \\
(\%)\end{array}$ \\
\hline 2.26 & Benzoic acid ${ }^{\mathrm{a}, \mathrm{b}, \mathrm{c}}$ & 1162 & 121 & 4.1 \\
\hline 5.81 & 3-Hydroxybenzoic acid ${ }^{\mathrm{a}, \mathrm{b}, \mathrm{c}}$ & 1563 & 137 & 5.2 \\
\hline 6.01 & 4-Hydroxybenzoic acid ${ }^{\mathrm{a}, \mathrm{b}, \mathrm{c}}$ & 1625 & 137 & 5.5 \\
\hline 8.49 & (2E)-3-(4-Hydroxyphenyl)prop-2-enoic acid (p-coumaric acid) ${ }^{a, b, c}$ & 1938 & 163 & 10.6 \\
\hline 8.42 & 3, 4, 5-Trihydroxybenzoic acid (gallic acid) (a,, $\mathrm{c}^{-}$ & 1943 & 169 & 5.5 \\
\hline 10.37 & (2E)-3-(4-Hydroxy-3-methoxyphenyl)prop-2-enoic acid (ferulic acid) ${ }^{\mathrm{a}, \mathrm{b}, \mathrm{c}}$ & 2091 & 193 & 3.7 \\
\hline 10.42 & 3-(3, 4-Dihydroxyphenyl)-2-propenoic acid (caffeic acid) ${ }^{\mathrm{a}, \mathrm{b}, \mathrm{c}}$ & 2130 & 179 & 3.9 \\
\hline 11.81 & 3-(4-Hydroxy-3, 5-dimethoxyphenyl)prop-2-enoic acid (sinapic acid) ${ }^{\mathrm{a}, \mathrm{b}, \mathrm{c}}$ & 2241 & 223 & 3.2 \\
\hline 12.74 & Delphinidin-3-O-glucoside ${ }^{\mathrm{a}, \mathrm{c}}$ & - & 464 & 8.5 \\
\hline 12.99 & Cyanidin-3-O-glucoside $\mathrm{a}^{\mathrm{a}, \mathrm{c}}$ & - & 457 & 6.6 \\
\hline 15.27 & Malvidin-3-O-glucoside $\mathrm{a}^{\mathrm{a}, \mathrm{c}}$ & - & 491 & 6.4 \\
\hline 16.33 & $\begin{array}{c}\text { (2R,2'R,3R,3'S,4R)-2, 2'-Bis(3, 4-dihydroxyphenyl)-3, 3',4, 4'-tetrahydro-2H,2'H-4,8'- } \\
\text { bichromene-3, 3',5, 5',7, 7'-hexol (procyanidin B1) }\end{array}$ & - & 579 & 8.8 \\
\hline 16.88 & $(2 \mathrm{R}, 3 \mathrm{~S})-2-(3,4 \text {-Dihydroxyphenyl)-3, 4-dihydro-2H-chromene-3, 5, 7-triol (catechin) })^{\mathrm{a}, \mathrm{b}}$ & 2859 & 289 & 1.8 \\
\hline 18.76 & Epicatechin $^{\mathrm{a}, \mathrm{b}, \mathrm{c}}$ & 2836 & 289 & 2.7 \\
\hline 19.92 & Quercetin-3-O-galactoside $\mathrm{e}^{\mathrm{a}, \mathrm{c}}$ & - & 363 & 4.9 \\
\hline 21.46 & Kaempferol-3-O-glucoside ${ }^{\text {a,c }}$ & - & 447 & 5.9 \\
\hline 21.85 & 2-(3, 4-Dihydroxyphenyl)-3, 5, 7-trihydroxy-4H-chromen-4-one (quercetin) $)^{\mathrm{a}, \mathrm{b}, \mathrm{c}}$ & 3163 & 301 & 4.6 \\
\hline 21.98 & 3, 5, 7-Trihydroxy-2-(4-hydroxyphenyl)-4H-chromen-4-one (kaempferol) ${ }^{\mathrm{a}, \mathrm{c}}$ & - & 285 & 2.1 \\
\hline
\end{tabular}

${ }^{a}$ RT: retention time; STD: standard compound; NIST 14 (compound identified by RI comparison with library). ${ }^{\mathrm{b}}$ RI: Kovats retention indices (RI) determined using a commercial hydrocarbon mixture (C9-C25) on the HP-5MS column (compound identified by Kovats retention indices comparison with literature values). ${ }^{\mathrm{C}} \mathrm{MS}$ : compound identified by mass spectra comparison with the Wiley library.

TABLE 5: LC-MS analysis results of the pomegranate peel extract.

\begin{tabular}{|c|c|c|c|c|}
\hline $\begin{array}{l}\mathrm{RT}^{\mathrm{a}} \\
(\mathrm{min})\end{array}$ & Compound & $\mathrm{RI}^{\mathrm{b}}$ & $\begin{array}{l}{[\mathrm{M}-} \\
\mathrm{H}]^{\mathrm{c}}\end{array}$ & $\begin{array}{c}\text { Percentage } \\
(\%)\end{array}$ \\
\hline 2.25 & Butanoic acid 2-hydroxymethylestera $^{\mathrm{b}}$ & 1361 & - & 3.1 \\
\hline 2.91 & Pyridine $e^{a, b, c}$ & 1172 & 80 & 2.4 \\
\hline 3.27 & $2,3,7,8$-Tetrahydroxy-chromeno $[5,4,3$-cde $]$ chromene- 5,10 -dione (ellagic acid) ${ }^{\mathrm{a}, \mathrm{b}, \mathrm{c}}$ & 3292 & 300 & 7.8 \\
\hline 4.01 & 1-Deoxy-2, 4-O,O-methylene-d-xylitol & - & - & 1.2 \\
\hline 4.45 & Gallic acide, ${ }^{\mathrm{a}, \mathrm{c}} \mathrm{c}$ & 1943 & 169 & 5.9 \\
\hline 5.01 & 3-(3, 4-Dihydroxyphenyl)-2-propenoic acid (caffeic acid) $)^{\mathrm{a}, \mathrm{b}, \mathrm{c}}$ & 2130 & 179 & 4.7 \\
\hline 6.99 & $n$-Heptyl acrylate $\mathrm{a}^{\mathrm{a}, \mathrm{b}, \mathrm{c}}$ & 1489 & - & 2.1 \\
\hline 7.45 & Benzoyl bromide ${ }^{a, b, c}$ & - & - & 1.4 \\
\hline 7.77 & 1, 2-Di(2-furyl)-1, 2-ethanedione $\mathrm{a}^{\mathrm{a}, \mathrm{b}, \mathrm{c}}$ & - & - & 1.1 \\
\hline 8.00 & Delphinidin 3, 5-diglucoside ${ }^{\mathrm{a}}$ & - & - & 8.8 \\
\hline 8.42 & $\begin{array}{l}\text { (1S, 3R, 4R, 5R)-3-\{[(2E)-3-(3, 4-Dihydroxyphenyl)prop-2-enoyl }] \text { oxy }\}-1,4,5- \\
\text { trihydroxycyclohexanecarboxylic acid (chlorogenic acid) })^{\mathrm{a}, \mathrm{b}, \mathrm{c}}\end{array}$ & 3098 & 353 & 7.5 \\
\hline 10.92 & 2,5 -Furandicarboxaldehyde $\mathrm{e}^{\mathrm{a}, \mathrm{b}}$ & 2467 & - & 3.2 \\
\hline 11.86 & 2-Furancarboxaldehyde 5-(hydroxymethyl) ${ }^{\mathrm{a}, \mathrm{b}}$ & 2509 & - & 2.8 \\
\hline 12.73 & Valoneic acid dilactone $\mathrm{a}^{\mathrm{a}}$ & - & - & 5.1 \\
\hline 16.33 & Catechin $^{\mathrm{a}, \mathrm{b}, \mathrm{c}}$ & 2859 & 289 & 10.2 \\
\hline 16.88 & Epicatechin $^{\mathrm{a}, \mathrm{b}, \mathrm{c}}$ & 2836 & 289 & 7.5 \\
\hline 18.77 & Rutin ${ }^{\mathrm{a}, \mathrm{c}}$ & - & 465 & 2.2 \\
\hline 24.11 & Granatin $\mathrm{A}^{\mathrm{a}}$ & - & - & 6.5 \\
\hline 25.16 & Granatin $\mathrm{B}^{\mathrm{a}}$ & - & - & 6.9 \\
\hline
\end{tabular}

${ }^{a}$ RT: retention time; STD: standard compound; NIST 14 (compound identified by RI comparison with library). ${ }^{\mathrm{b}} \mathrm{RI}$ : Kovats retention indices (RI) determined using a commercial hydrocarbon mixture (C9-C25) on the HP-5MS column (compound identified by Kovats retention indices comparison with literature values). ${ }^{c} \mathrm{MS}$ : compound identified by mass spectra comparison with the Wiley library.

spectra suggests that the AgNPs were capped by organic constituents of the black currant, apricot, grape pomace, and pomegranate peel extracts.

FT-IR measurements were carried out to identify the possible compounds in the extracts responsible for capping leading to efficient stabilization of the silver nanoparticles (Figure 10). The FT-IR spectrum of the samples under the study had almost the same set of absorption bands and differed only in the intensity and slight shift of some bands. FT-IR spectra of grape pomace and pomegranate peel extracts before reaction showed several peaks at around $3400 \mathrm{~cm}^{-1}$ which can be assigned to $v(\mathrm{OH})$ vibrations of polyphenols $[4,9,52]$. The peaks at $1620 \mathrm{~cm}^{-1}, 1140 \mathrm{~cm}^{-1}$, $1360 \mathrm{~cm}^{-1}$, and $1050 \mathrm{~cm}^{-1}$ corresponds to the $\nu(\mathrm{C}=\mathrm{O})$, while 


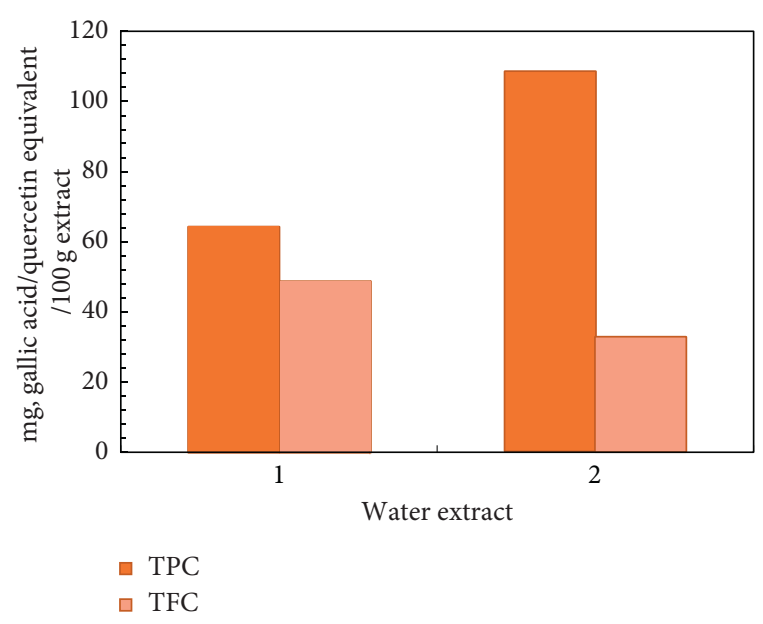

Figure 4: Total phenolic (TPC) and flavonoid (TFC) contents of the aqueous grape pomace (1) and pomegranate peel (2) extracts.

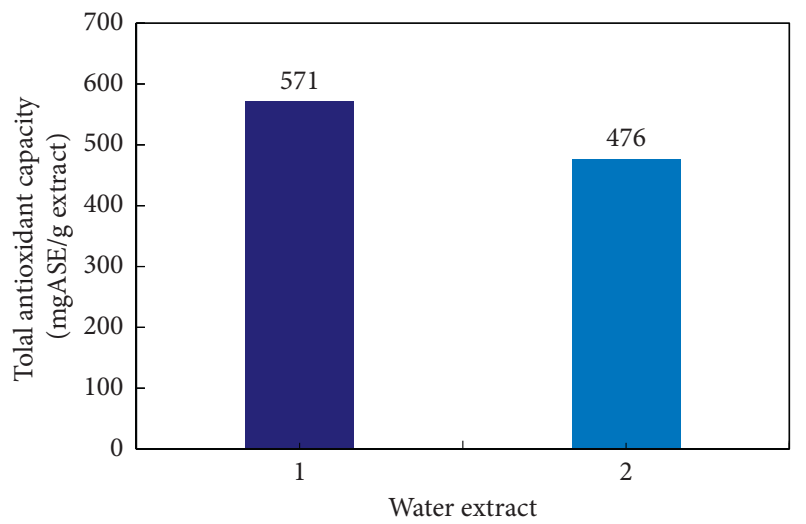

FIgURE 5: Total antioxidant capacity (mg ASE/g extract) of the aqueous grape pomace (1) and pomegranate peel (2) extracts were evaluated by the phosphomolybdenum method.

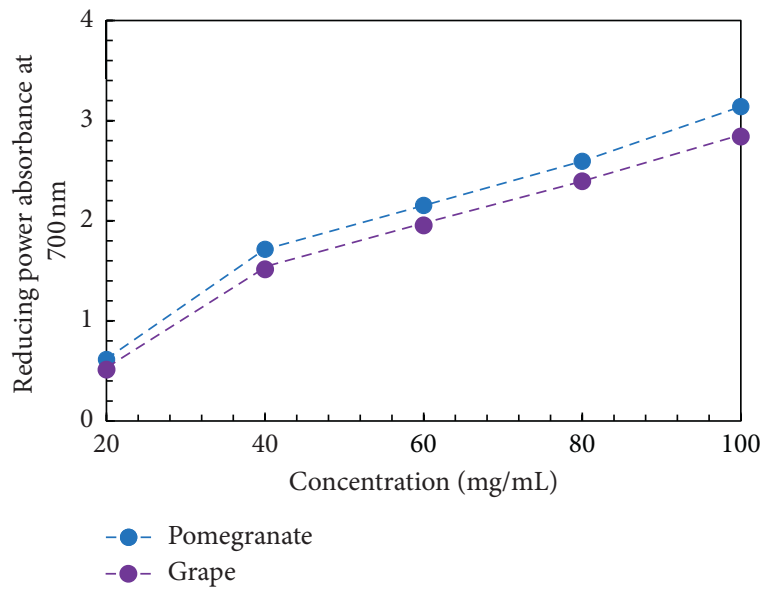

FIGURE 6: Reducing power of the aqueous grape pomace and pomegranate peel extracts was evaluated by the FRAP assay.

the absorptions at $1652 \mathrm{~cm}^{-1}$ may be referred to $\mathrm{C}=\mathrm{C}$ vibrations or aromatic ring $v(\mathrm{C}=\mathrm{C})$. Absorption bands at $2910 \mathrm{~cm}^{-1}$ are attributed to $\mathrm{C}-\mathrm{H}$ bonds in aldehydes [31, 52].

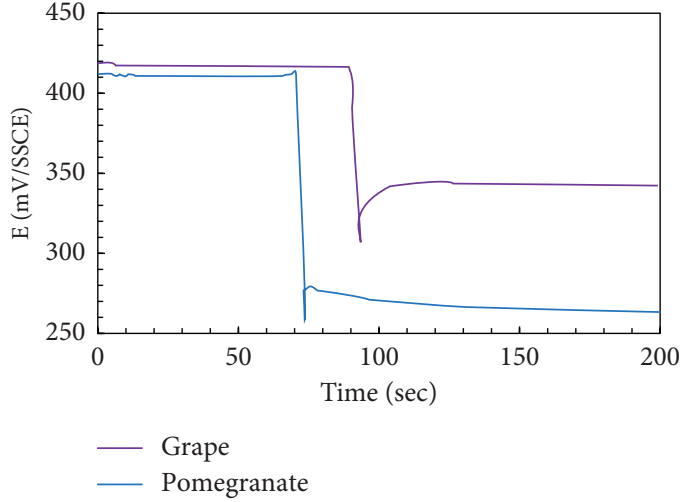

Figure 7: The $\mathrm{Ag}^{+} \mid \mathrm{Ag}$ electrode potential variation with time during the "green" synthesis with extracts at $80^{\circ} \mathrm{C}$.

TABLE 6: The degree of conversion of Ag in the "green" synthesis.

\begin{tabular}{lcc}
\hline & Extract & Degree of conversion (\%) \\
\hline 1 & Grape pomace & 93.3 \\
2 & Pomegranate peels & 99.7 \\
\hline
\end{tabular}

Comparison of the FTIR spectra of the extracts and sample AgNPs synthesis with the extract showed a significant difference between the type and intensity of the observed peaks. The shift of peaks and reduction in bands in the range $1500-1600,1000-1200$, and $3500-3200 \mathrm{~cm}^{-1}$ after reduction indicates the oxidation of the corresponding functional groups and may be attributed to the reduction of $\mathrm{Ag}^{+}$ions to $\mathrm{Ag}^{0}$ nanoparticles. The FT-IR spectrum of the synthesized GPE-AgNPs and PPE-AgNPs showed absorption peaks at $1645 \mathrm{~cm}$ and $3440 \mathrm{~cm}^{-1}$. The weak peak detected at $1645 \mathrm{~cm}^{-1}$ was assigned as carbonyl groups that were almost decreased in the FT-IR band. It could indicate that the carbonyl groups might participate in the reduction of $\mathrm{AgNO}_{3}$. The absence of peaks at $1264 \mathrm{~cm}^{-1}, 1289 \mathrm{~cm}^{-1}$, and $1347 \mathrm{~cm}^{-1}$ may be due to the capping action of the $\mathrm{C}-\mathrm{O}$ group in the synthesis of AgNPs.

The results of SEM analyses are presented in Figure 11. The SEM analysis provides further information about the morphology of the synthesized AgNPs. The SEM images revealed the formation of individual silver nanoparticles as well as several aggregates. Spherical nanoparticles were evidenced from the SEM image with few agglomerations, which may be because of the stabilization of the organic compounds present in the extracts. More agglomeration was observed in the suspensions of nanoparticles derived from pomegranate peel extract as the reductant, which indicates lower stability of the system. In meantime, the AgNPs obtained with GPE do not tend to agglomerate even when the solution is diluted before SEM. This confirms the higher stabilization properties of GPE compared to PPE.

The antibacterial properties of GPE-AgNPs and PPEAgNPs were evaluated using the agar well diffusion method and the results were expressed as a zone of inhibition in $\mathrm{mm}$ 


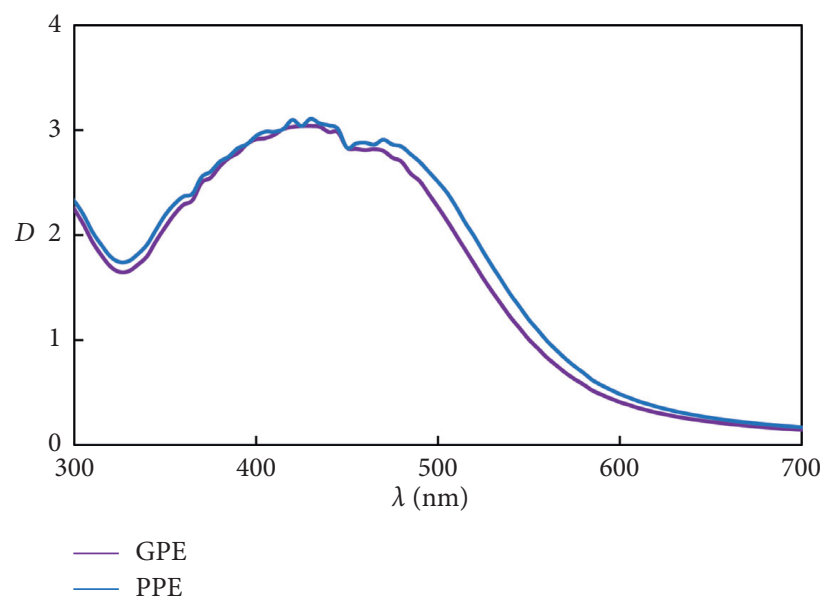

Figure 8: UV-Vis absorption spectra of GPE-AgNPs and PPE-AgNPs after 30 min of reaction displaying the characteristic surface plasmon resonance band at $440 \mathrm{~nm}$.

TABLE 7: Characteristics of AgNPs synthesized using black currant, apricot, grape pomace, and pomegranate peel extracts.

\begin{tabular}{lcr}
\hline System & Average particle-sized AgNPs (nm) & Zeta potential \\
\hline GPE-AgNPs & $50-90 \mathrm{~nm}$ & -25.31 \\
PPE-AgNPs & $40-54 \mathrm{~nm}$ & -38.82 \\
\hline
\end{tabular}

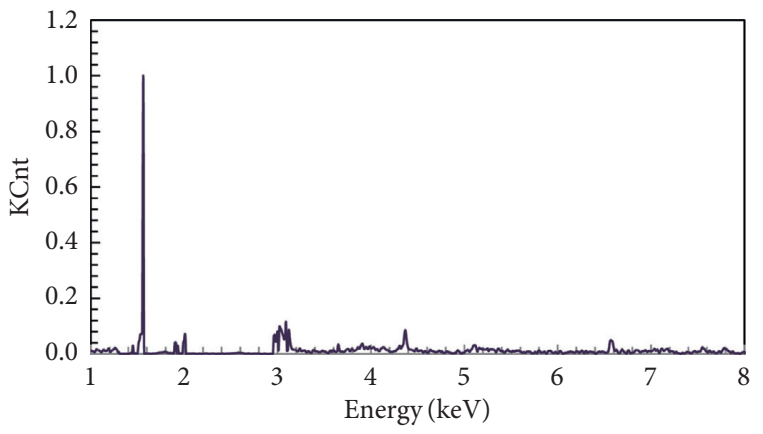

(a)

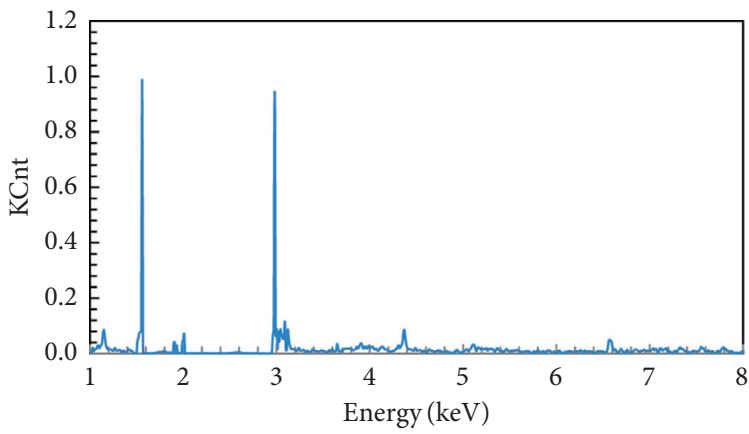

(b)

Figure 9: EDX spectra of GPE-AgNPs and PPE-AgNP.

(Table 8). The Gram-negative bacteria showed a lower zone of inhibition, while Gram-positive bacteria showed better results. The inhibitory effect of GPE-AgNPs and PPE-AgNPs on the growth of bacteria was observed after incubation at $37^{\circ} \mathrm{C}$ for $24 \mathrm{~h}$. After $24 \mathrm{~h}$ of incubation, the observed zones of growth inhibition treated by GPE-AgNPs were $3.9 \pm 0.1 \mathrm{~mm}$ (B. subtilis) and $2.1 \pm 0.1$ (E. coli), respectively. After $24 \mathrm{~h}$ of incubation, the observed zones of growth inhibition treated by PPE-AgNPs were $2.7 \pm 0.1 \mathrm{~mm}$ (B. subtilis) and $2.2 \pm 0.1$ (E. coli), respectively.

As a general result, it was observed that the GPE-AgNPs and PPE-AgNPs showed higher activity against B. subtilis compared with E. coli. Two primary mechanisms of antimicrobial action of AgNPs have been recognized: (1) contact killing and (2) ion-mediated killing [55, 56]. Antibacterial mechanisms through direct contact occur by adhesion of
AgNPs onto the surface of the cell wall and penetration into it. Connecting AgNPs to proteins in bacteria membranes leads to membrane damage that can cause leakage of cellular contents and bacterial death. After penetrating the membrane, AgNPs can also enter the bacterial cytoplasm.

Additionally, the antibacterial properties of GPE-AgNPs and PPE-AgNPs were evaluated using a liquid medium. As shown in Figure 12, the synthesized GPE-AgNPs and PPEAgNPs exhibited significant antibacterial activity in a concentration-dependent manner against E. coli. The inhibitory efficacy (MIC) assay demonstrated a reduction in E. coli at AgNPs concentrations above $7.5 \%$ and $10 \%$ solutions of GPE-AgNPs and PPE-AgNPs, respectively. Thus, the synthesized AgNPs could be a good antimicrobial agent.

Although the wastes of the above-studied extracts have already been used for the synthesis of silver nanoparticles 


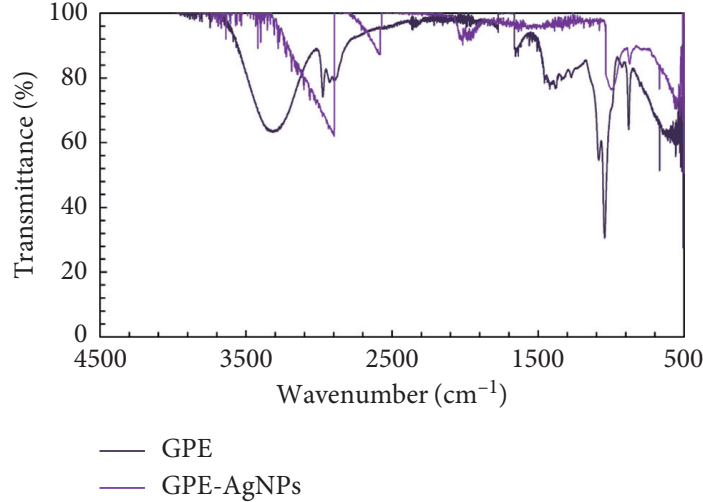

(a)

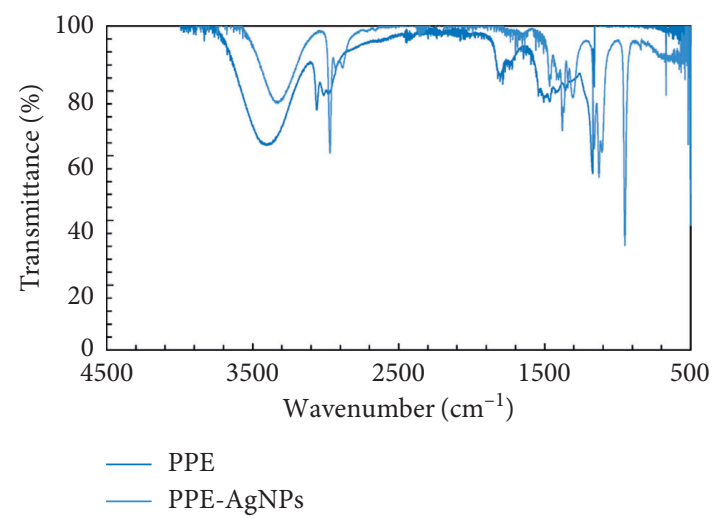

(b)

FIGURE 10: FT-IR spectra of aqueous black currant, apricot, grape pomace, and pomegranate peel extracts and GPE-AgNPs and PPE-AgNP.

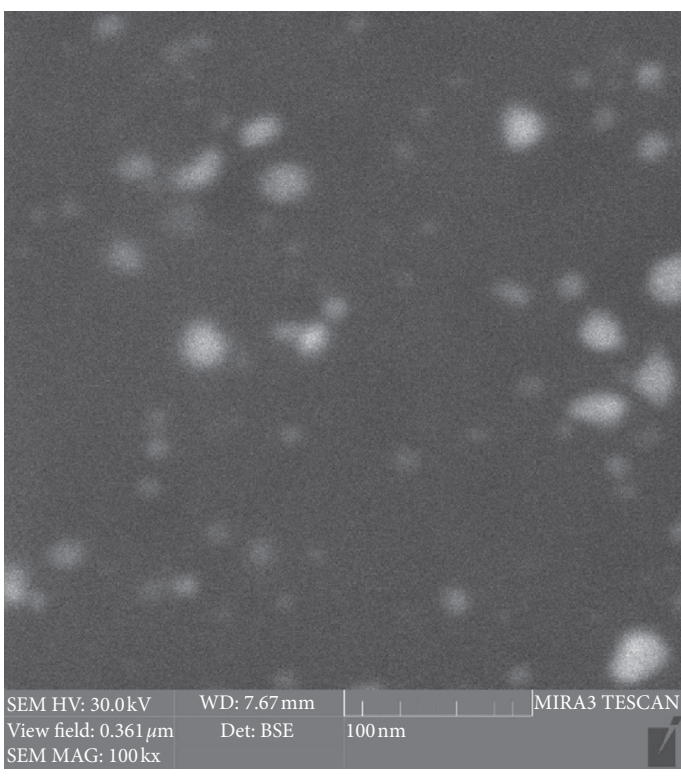

(a)

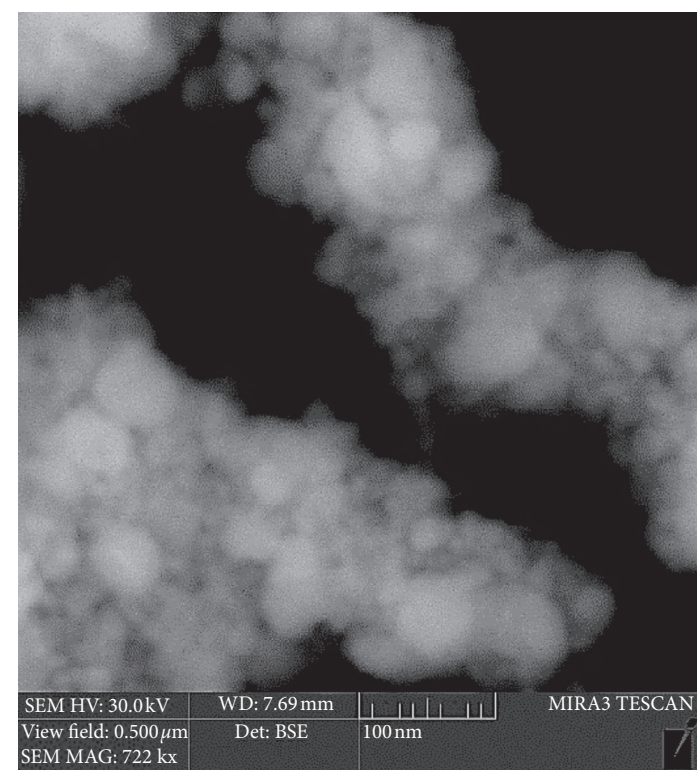

(b)

Figure 11: SEM images of silver nanoparticles $\left(\mathrm{C}\left(\mathrm{Ag}^{+}\right)=10 \mathrm{mmol} / \mathrm{L}, \tau=30 \mathrm{~min}\right.$, and ratio $\mathrm{AgNO}_{3}$ : extract of grape pomace $(\mathrm{a})$ and pomegranate peel $(\mathrm{b})$ extracts $(\mathrm{mL})=1: 1)$.

TABLe 8: Antibacterial activity of GPE-AgNPs and PPE-AgNPs.

\begin{tabular}{|c|c|c|c|c|c|}
\hline \multirow{3}{*}{ Bacteria strains } & \multirow{3}{*}{ Stirred heater } & \multicolumn{4}{|c|}{ Zone of inhibition $(\mathrm{mm})$} \\
\hline & & \multicolumn{2}{|c|}{$24 \mathrm{~h}$} & \multicolumn{2}{|c|}{$48 \mathrm{~h}$} \\
\hline & & GPE-AgNPs & PPE-AgNPs & GPE-AgNPs & PPE-AgNPs \\
\hline E. coli & - & $2.9 \pm 0.1$ & $2.2 \pm 0.1$ & $3.4 \pm 0.1$ & $3.1 \pm 0.1$ \\
\hline B. subtilis & - & $3.9 \pm 0.1$ & $2.7 \pm 0.1$ & $4.6 \pm 0.1$ & $3.4 \pm 0.1$ \\
\hline
\end{tabular}

and are presented in the literature, their preliminary oxidation makes it possible to reduce the synthesis time and to limit the use of an ecologically safe extractant (water) instead of organic solvents. To illustrate the important benefits of the utilization of preoxidized extract for the synthesis of AgNPs, it was compared with other studies, and the recent 


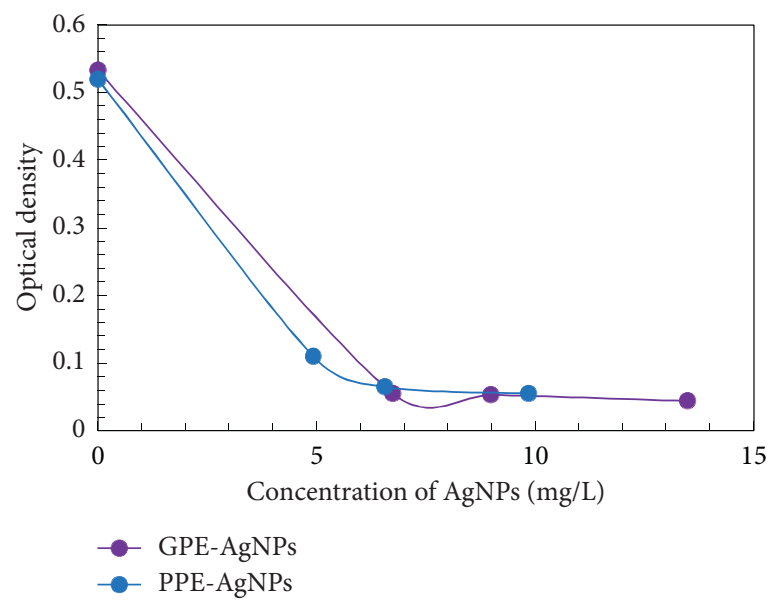

Figure 12: Optical density of test tubes with E. coli culture and different concentrations of AgNP grape pomaces and pomegranate peel extracts after 24 hours of cultivation.

TABle 9: A summary of plant-based extracts as Ag reducing agent.

\begin{tabular}{lccc}
\hline Plant/Fruit & Time of the synthesis AgNPs & Extractant & Reference \\
\hline & $10-15 \mathrm{~min}$ & Boiled for water & Water \\
Peels of Punica granatum & $24 \mathrm{~h}$ & Plasma chemical treatment & {$[51]$} \\
& $15 \mathrm{~min}$ & Ethanol & {$[5]$} \\
Grape pomace & $24 \mathrm{~h}$ & Aqueous solution of $\mathrm{Na}_{2} \mathrm{CO}_{3}(2.5 \%)$ and $\mathrm{Na}_{2} \mathrm{SO}_{3}(2.5 \%)$ & {$[56]$} \\
\hline
\end{tabular}

outcomes to produce the AgNPs by extract are summarized in Table 9.

Table summarized the application of plant-based extracts as AgNPs reducing agents. Clearly, the oxidized extracts show the shortest time of reduction of $\mathrm{Ag}^{+}$cations to the NPs in comparison with the extracts described in the literature.

\section{Conclusions}

The obtained results show high potential for the usage of wastes in corrosion and scale inhibition or nanomaterial development and production processes.

(1) Inhibition of scaling and corrosion was investigated in thermal scaling conditions on the surface of the electrode manufactured from mild steel. The LPR technique was applied to measure the corrosion rate, and the scaling rate was determined gravimetrically. The extracts were found to inhibit the corrosion rate 2-3 times, while only radish cake extract inhibited both the corrosion and scaling rates.

(2) The result obtained in this investigation is remarkably interesting in terms of the identification of potential fruit and berry crops for the synthesis of silver nanoparticles. The present study firstly documented the synthesis and characterization of silver nanoparticles by using previously oxidized aqueous black currant, apricot, grape pomace, and pomegranate peel extracts.

(3) Detailed gas chromatography-mass spectrometry (LCMS) results established that polyphenolic compounds and flavonoids predominate in the apricot, grape, black currant pomace, and pomegranate peel extracts. The pomegranate peel and grape pomace extracts contained higher amounts of phenolics and flavonoids when compared with the black currant and apricot pomace extract. The grape pomace and pomegranate peel extract showed higher reducing power measured by the spectrophotometry method, as well as higher efficiency for "green" synthesis of silver nanoparticles. In summary, SEM, EDX, and UV-Vis spectroscopy confirmed the successful eco-friendly method for the synthesis of AgNPs using extracts. The synthesized GPE-AgNPs and PPE-AgNPs exhibit mainly a spherical shape with small size $(40$ to $60 \mathrm{~nm}$ ). The sharp peak detected near $3 \mathrm{keV}$ approves the successful synthesis of AgNPs by the use of the extracts. The AgNPs showed antimicrobial activity against common pathogenic bacteria E. coli. and B. subtilis.

\section{Data Availability}

All data generated or analyzed during this study are included within the article.

\section{Conflicts of Interest}

The authors declare that they have no conflicts of interest.

\section{Acknowledgments}

This work was supported by the Ministry of Education and Science of Ukraine (grant no: 2223, 2019). 


\section{References}

[1] C. M. Ajila, S. K. Brar, M. Verma, and U. J. S. Prasada Rao, "Sustainable solutions for agro processing waste management: an overview," Strategies for Sustainability. Environmental Protection Strategies for Sustainable Development, pp. 65-109, Springer, Dordrecht, Netherlands, 2011.

[2] T. Quang Huy, N. van Quy, and L. Anh-Tuan, "Silver nanoparticles: synthesis, properties, toxicology, applications and perspectives," Advances in Natural Sciences: Nanoscience and Nanotechnology, vol. 4, no. 3, Article ID 033001, 2013.

[3] M. Darroudi, M. B. Ahmad, A. H. Abdullah, N. A. Ibrahim, and K. Shameli, "Effect of accelerator in green synthesis of silver nanoparticles," International Journal of Molecular Sciences, vol. 11, no. 10, pp. 3898-3905, 2010.

[4] B. Ankamwar, C. Damle, A. Ahmad, and M. Sastry, "Biosynthesis of gold and silver nanoparticles using emblica officinalis fruit extract, their phase transfer and transmetallation in an organic solution," Journal of Nanoscience and Nanotechnology, vol. 5, no. 10, pp. 1665-1671, 2005.

[5] M. Skiba and V. Vorobyova, "Green synthesis of silver nanoparticles using grape pomace extract prepared by plasma-chemical assisted extraction method," Molecular Crystals and Liquid Crystals, vol. 671, no. 1, pp. 142-151, 2018.

[6] S. Pimentel-Moral, M. d. 1. L. Cádiz-Gurrea, C. RodríguezPérez, and A. Segura-Carretero, "Recent advances in extraction technologies of phytochemicals applied for the revaluation of agri-food by-products," in Functional and Preservative Properties of Phytochemicals, pp. 209-239, Elsevier, Amsterdam, Netherlands, 2020.

[7] K. V. G. Ravikumar, S. V. Sudakaran, K. Ravichandran, M. Pulimi, C. Natarajan, and A. Mukherjee, "Green synthesis of NiFe nano particles using Punica granatum peel extract for tetracycline removal," Journal of Cleaner Production, vol. 210, pp. 767-776, 2019.

[8] N. Ahmad and S. Sharma, "Biosynthesis of silver nanoparticles from biowaste pomegranate peels," International Journal of Nanoparticles, vol. 5, no. 3, pp. 185-195, 2012.

[9] N. Ahmad, S. Sharma, and R. Rai, "Rapid green synthesis of silver and gold nanoparticles using peels of Punica granatum," Advanced Materials Letters, vol. 3, no. 5, pp. 376-380, 2012.

[10] S. S. Shankar, A. Rai, A. Ahmad, and M. Sastry, "Rapid synthesis of $\mathrm{Au}, \mathrm{Ag}$, and bimetallic Au core-Ag shell nanoparticles using Neem (Azadirachta indica) leaf broth," Journal of Colloid and Interface Science, vol. 275, no. 2, pp. 496-502, 2004.

[11] H. I. Abdel-Shafy and M. S. M. Mansour, "Green synthesis of metallic nanoparticles from natural resources and food waste and their environmental application," Green Metal Nanoparticles, vol. 117, pp. 321-385, 2018.

[12] E. Alibakhshi, M. Ramezanzadeh, S. A. Haddadi, G. Bahlakeh, B. Ramezanzadeh, and M. Mahdavian, "Persian Liquorice extract as a highly efficient sustainable corrosion inhibitor for mild steel in sodium chloride solution," Journal of Cleaner Production, vol. 210, pp. 660-672, 2019.

[13] V. I. Vorobyova, M. I. Skiba, and I. M. Trus, “Apricot pomaces extract (Prunus armeniaca l.) as a highly efficient sustainable corrosion inhibitor for mild steel in sodium chloride solution," International Journal of Corrosion and Scale Inhibition, vol. 8, no. 4, pp. 1060-1083, 2019.

[14] P. Refait, C. Rahal, and M. Masmoudi, "Corrosion inhibition of copper in $0.5 \mathrm{M} \mathrm{NaCl}$ solutions by aqueous and hydrolysis acid extracts of olive leaf," Journal of Electroanalytical Chemistry, vol. 859, Article ID 113834, 2020.
[15] G. Vasyliev, V. Vorobyova, and T. Zhuk, "Raphanus sativus L. extract as a scale and corrosion inhibitor for mild steel in tap water," Journal of Chemistry, vol. 2020, Article ID 5089758, 2020.

[16] V. Vorob'iova, O. Chyhyrynets, and O. Vasyl'kevych, "Mechanism of formation of the protective flms on steel by volatile compounds of rapeseed cake," Materials Science, vol. 50, no. 5, pp. 726-735, 2015.

[17] O. V. Zillich, U. Schweiggert-Weisz, P. Eisner, and M. Kerscher, "Polyphenols as active ingredients for cosmetic products," International Journal of Cosmetic Science, vol. 37, no. 5, pp. 455-464, 2015.

[18] G.-F. Deng, X. Lin, X.-R. Xu, L.-L. Gao, J.-F. Xie, and H.-B. Li, "Antioxidant capacities and total phenolic contents of 56 vegetables," Journal of Functional Foods, vol. 5, no. 1, pp. 260-266, 2013.

[19] M. Castrica, R. Rebucci, C. Giromini, M. Tretola, D. Cattaneo, and A. Baldi, "Total phenolic content and antioxidant capacity of agri-food waste and by-products," Italian Journal of Animal Science, vol. 18, no. 1, pp. 1-6, 2018.

[20] Y. Lyu, M. Yu, Q. Liu et al., "Synthesis of silver nanoparticles using oxidized amylose and combination with curcumin for enhanced antibacterial activity," Carbohydrate Polymers, vol. 230, Article ID 115573, 2019.

[21] V. Vorobyova, G. Vasyliev, and M. Skiba, "Eco-friendly "green" synthesis of silver nanoparticles with the black currant pomace extract and its antibacterial, electrochemical and antioxidant activity," Applied Nanoscience, vol. 10, 2020.

[22] G. Vasyliev, V. Vorobyova, M. Skiba, and L. Khrokalo, "Green synthesis of silver nanoparticles using waste products (apricot and black currant pomace) aqueous extracts and their characterization," Advances in Materials Science and Engineering, vol. 2020, no. 3, Article ID 4505787, 11 pages, 2020.

[23] M. Chaussemier, E. Pourmohtasham, D. Gelus et al., "State of art of natural inhibitors of calcium carbonate scaling. a review article," Desalination, vol. 356, pp. 47-55, 2015.

[24] Z. Belarbi, J. Gamby, L. Makhloufi, B. Sotta, and B. Tribollet, "Inhibition of calcium carbonate precipitation by aqueous extract of Paronychia argentea," Journal of Crystal Growth, vol. 386, pp. 208-214, 2014.

[25] H. Cheap-Charpentier, D. Gelus, N. Pécoul et al., "Antiscalant properties of Spergularia rubra and Parietaria officinalis aqueous solutions," Journal of Crystal Growth, vol. 443, pp. 43-49, 2016.

[26] E. A. Noor, "The impact of some factors on the inhibitory action of Radish seeds aqueous extract for mild steel corrosion in $1 \mathrm{M} \mathrm{H}_{2} \mathrm{SO}_{4}$ solution," Materials Chemistry and Physics, vol. 131, no. 1-2, pp. 160-169, 2011.

[27] D. Li, P. Zhang, X. Guo, X. Zhao, and Y. Xu, "The inhibition of mild steel corrosion in $0.5 \mathrm{M} \mathrm{H}_{2} \mathrm{SO}_{4}$ solution by radish leaf extract," RSC Advances, vol. 9, no. 70, pp. 40997-41009, 2019.

[28] I. Radojčić, K. Berković, S. Kovač, and J. Vorkapić-Furač, "Natural honey and black radish juice as tin corrosion inhibitors," Corrosion Science, vol. 50, no. 5, pp. 1498-1504, 2008.

[29] J. A. Selvi, S. Rajendran, V. G. Sri, A. J. Amalraj, and B. Narayanasamy, "Corrosion inhibition by beet root extract," Portugaliae Electrochimica Acta, vol. 27, no. 1, 2009.

[30] G. Vasyliev and V. Vorobiova, "Rape grist extract (Brassica napus) as a green corrosion inhibitor for water systems," Materials Today: Proceedings, vol. 6, pp. 178-186, 2019.

[31] J. C. Sánchez-Rangel, J. Benavides, J. B. Heredia, L. CisnerosZevallos, and D. A. Jacobo-Velázquez, "The Folin-Ciocalteu assay revisited: improvement of its specificity for total 
phenolic content determination," Analytical Methods, vol. 5, no. 21, p. 5990, 2013.

[32] A. Arvouet-Grand, B. Vennat, A. Pourrat, and P. Legret, "Standardization of propolis extract and identification of principal constituents," Journal of Pharmacy Belgium, vol. 49, pp. 462-468, 1994.

[33] P. Prieto, M. Pineda, and M. Aguilar, "Spectrophotometric quantitation of antioxidant capacity through the formation of a phosphomolybdenum complex: specific application to the determination of vitamin E," Analytical Biochemistry, vol. 269, no. 2, pp. 337-341, 1999.

[34] K. Taipong, U. Boonprakob, K. Crosby, L. Cisneros-Zevallos, and D. Hawkins Byrne, "Comparison of ABTS, DPPH, FRAP, and ORAC assays for estimating antioxidant activity from guava fruit extracts," Journal of Food Composition and Analysis, vol. 19, no. 6-7, pp. 669-675, 2006.

[35] W. Rhimi, R. Hlel, I. Ben Salem, A. Boulila, A. Rejeb, and M. Saidi, "Dittrichia viscosa L. ethanolic extract based ointment with antiradical, antioxidant, and healing wound activities," BioMed Research International, vol. 2019, Article ID 4081253, 10 pages, 2019.

[36] H. S. Vasyl'Ev, "Measurement of polarization resistance with computer logging of results," Materials Science, vol. 48, no. 5, pp. 694-696, 2013.

[37] H. S. Vasyl'ev and Y. S. Herasymenko, "Corrosion meters of new generation based on the improved method of polarization resistance," Materials Science, vol. 52, no. 5, pp. 722-731, 2017.

[38] G. Vasyliev, "Polarization resistance measurement in tap water: the influence of rust electrochemical activity," Journal of Materials Engineering and Performance, vol. 26, no. 8, pp. 3939-3945, 2017.

[39] Y.S. Herasymenko and H. S. Vasyl'ev, "A two-step method for the evaluation of corrosion rate in metals," Materials Science, vol. 45, no. 6, pp. 899-904, 2009.

[40] G. Vasyliev, S. Vasylieva, A. Novosad, and Y. Gerasymenko, "Ultrasonic modification of carbonate scale electrochemically deposited in tap water," Ultrasonics Sonochemistry, vol. 48, pp. 57-63, 2018.

[41] O. E. Chyhyrynets, Y. F. Fateev, V. I. Vorobiova, and M. I. Skyba, "Study of the mechanism of action of the isopropanol extract of rapeseed oil cake on the atmospheric corrosion of copper," Materials Science, vol. 51, no. 5, pp. 644-651, 2016.

[42] V. Vorobyova, M. Skiba, and O. Chygyrynets', "A novel ecofriendly vapor phase corrosion inhibitor of mild steel," Pigment \& Resin Technology, vol. 48, no. 2, pp. 137-147, 2019.

[43] V. Vorobyova, O. Chygyrynets, M. Skiba, T. Zhuk, I. Kurmakova, and O. Bondar, "A comprehensive study of grape cake extract and its active components as effective vapour phase corrosion inhibitor of mild steel," International Journal of Corrosion and Scale Inhibition, vol. 7, pp. 185-202, 2018.

[44] V. Vorobyova, O. Chygyrynetś, M. Skiba, I. Kurmakova, and O. Bondar, "Self-assembled monoterpenoid phenol as vapor phase atmospheric corrosion inhibitor of carbon steel," International Journal of Corrosion and Scale Inhibition, vol. 6, no. 4, pp. 485-503, 2017.

[45] V. I. Vorobyova, M. I. Skiba, A. S. Shakun, and S. V. Nahirniak, "Relationship between the inhibition and antioxidant properties of the plant and biomass wastes extracts-a review," International Journal of Corrosion and Scale Inhibition, vol. 8, pp. 150-178, 2019.
[46] V. Vorobyova, O. Chygyrynets, and M. Skiba, "4-hydroxy-3methoxybenzaldehyde as a volatile inhibitor on the atmospheric corrosion of carbon steel," Journal of Chemical Technology and Metallurgy, vol. 53, pp. 336-345, 2018.

[47] V. Vorobyova, M. Skiba, O. Chygyrynets', M. Skiba, I. Trus, and S. Frolenkova, "Grape pomace extract as green vapor phase corrosion inhibitor," Chemistry \& Chemical Technology, vol. 12, no. 3, pp. 410-418, 2018.

[48] E. Bruno Romanini, L. Misturini Rodrigues, A. Finger, T. Perez Cantuaria Chierrito, M. Regina da Silva Scapim, and G. Scaramal Madrona, "Ultrasound assisted extraction of bioactive compounds from BRS Violet grape pomace followed by alginate-Ca ${ }^{2+}$ encapsulation," Food Chemistry, vol. 338, p. 128101, 2021.

[49] J. E. Young, Z. Pan, H. E. Teh et al., "Phenolic composition of pomegranate peel extracts using an liquid chromatographymass spectrometry approach with silica hydride columns," Journal of Separation Science, vol. 40, no. 7, pp. 1449-1456, 2017.

[50] N. Swilam and K. A. Nematallah, "Polyphenols profile of pomegranate leaves and their role in green synthesis of silver nanoparticles," Scientific Reports, vol. 10, p. 14851, 2020.

[51] T. J. I. Edison and M. G. Sethuraman, "Biogenic robust synthesis of silver nanoparticles using Punica granatum peel and its application as a green catalyst for the reduction of an anthropogenic pollutant 4-nitrophenol," Spectrochimica Acta Part A: Molecular and Biomolecular Spectroscopy, vol. 104, pp. 262-264, 2013.

[52] M. F. Zayed, W. H. Eisa, S. M. El-kousy, W. K. Mleha, and N. Kamal, "Ficus retusa-stabilized gold and silver nanoparticles: controlled synthesis, spectroscopic characterization, and sensing properties," Spectrochimica Acta Part A: Molecular and Biomolecular Spectroscopy, vol. 214, pp. 496-512, 2019.

[53] M. Skiba, V. Vorobyova, A. Pivovarov, A. Shakun, E. Gnatko, and I. Trus, "“Green” synthesis of nanoparticles of precious metals: antimicrobial and catalytic properties," Eastern-European Journal of Enterprise Technologies, vol. 5, no. 6 (95), pp. 51-58, 2018.

[54] P. Chettri, V. S. Vendamani, A. Tripathi, M. K. Singh, A. P. Pathak, and A. Tiwari, "Green synthesis of silver nanoparticle-reduced graphene oxide using Psidium guajava and its application in SERS for the detection of methylene blue," Applied Surface Science, vol. 406, pp. 312-318, 2017.

[55] S. Devanesan, M. S. AlSalhi, R. V. Balaji et al., "Antimicrobial and cytotoxicity effects of synthesized silver nanoparticles from Punica granatum peel extract," Nanoscale Research Letters, vol. 13, p. 315, 2018.

[56] G. D. Saratale, R. G. Saratale, D.-S. Kim, D.-Y. Kim, and H.-S. Shin, "Exploiting fruit waste grape pomace for silver nanoparticles synthesis, assessing their antioxidant, antidiabetic potential and antibacterial activity against human pathogens: a novel approach," Nanomaterials, vol. 10, no. 8, p. 1457, 2020.

[57] N. Hashim, M. Paramasivam, J. S. Tan et al., "Green mode synthesis of silver nanoparticles using Vitis vinifera's tannin and screening its antimicrobial activity/apoptotic potential versus cancer cells," Materials Today Communications, vol. 25, Article ID 101511, 2020. 